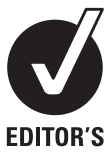

CHOICE

\title{
Outpatient pulmonary rehabilitation following acute exacerbations of COPD
}

John M Seymour, ${ }^{1}$ Lauren Moore, ${ }^{2}$ Caroline J Jolley, ${ }^{1}$ Katie Ward, ${ }^{1}$ Jackie Creasey, ${ }^{3}$ Joerg S Steier, ${ }^{1}$ Bernard Yung, ${ }^{3}$ William D-C Man, ${ }^{4}$ Nicholas Hart, ${ }^{2}$ Michael I Polkey, ${ }^{4}$ John Moxham ${ }^{1}$

- Supplementary data are published online only. To view this file please visit the journal online http://thorax.bmj.com/ content/vol65/issue5

${ }^{1}$ King's College London School of Medicine, London, UK

${ }^{2}$ Guy's and St Thomas' NHS Foundation Trust, London, UK ${ }^{3}$ Basildon and Thurrock NHS Foundation Trust, Essex, UK

${ }^{4}$ Royal Brompton and Harefield NHS Trust, London, UK

\section{Correspondence to}

Dr John Seymour, Department of Respiratory Medicine, King's College Hospital, London SE5 9RJ, UK;

john.seymour@kcl.ac.uk

Received 23 July 2009 Accepted 16 January 2010

\begin{abstract}
Background Exacerbations of chronic obstructive pulmonary disease (COPD) are characterised by increased dyspnoea, reduced quality of life and muscle weakness. Re-exacerbation and hospital admission are common. Pulmonary rehabilitation (PR) administered after hospital admission for an exacerbation can improve quality of life and exercise capacity.

Objective To determine whether outpatient postexacerbation PR (PEPR) could reduce subsequent hospital admission episodes.

Methods Patients admitted to hospital for an exacerbation of COPD were randomised to receive either usual follow-up care (UC) or PEPR after discharge. Hospital admission and emergency department attendances for COPD exacerbations were recorded over a 3-month period and analysed on an intention-to-treat basis. Secondary outcomes included exercise capacity and quadriceps strength.
\end{abstract}

Results 60 patients underwent concealed randomisation at the time of their hospital discharge (UC: $n=30$, mean (SD) age 65 (10) years, forced expiratory volume in $1 \mathrm{~s}$ $\left(\mathrm{FEV}_{1}\right) 52$ (22)\% predicted; PEPR: $n=30,67(10)$ years, $52(20) \%$ predicted). The proportion of patients readmitted to hospital with an exacerbation was $33 \%$ in the UC group compared with $7 \%$ in those receiving PEPR (OR 0.15, 95\% Cl 0.03 to $0.72, p=0.02$ ). The proportion of patients that experienced an exacerbation resulting in an unplanned hospital attendance (either admission or review and discharge from the emergency department) was $57 \%$ in the UC group and $27 \%$ in those receiving PEPR (OR 0.28, $95 \% \mathrm{Cl} 0.10$ to $0.82, \mathrm{p}=0.02$ ).

Conclusions Post-exacerbation rehabilitation in COPD can reduce re-exacerbation events that require admission or hospital attendance over a 3-month period. Clinical Trials Registration Number NCT00557115.

\section{INTRODUCTION}

Exacerbations of chronic obstructive pulmonary disease (COPD) represent a challenge for healthcare providers. COPD is increasing worldwide ${ }^{1}$ and methods of reducing exacerbations have been the focus of numerous pharmacological ${ }^{2}{ }^{3}$ and nonpharmacological interventional trials. ${ }^{4}{ }^{5}$ Exacerbations are characterised by an increase in breathlessness and are associated with reduced quality of life and exercise capacity. ${ }^{6} 7$ Following an exacerbation, patients are at increased risk of re-exacerbation or hospitalisation. ${ }^{89}$ An audit of COPD in the UK found that approximately one-third of patients have a further admission within 90 days. ${ }^{8}$
Reduced daily activity and quadriceps strength predict healthcare utilisation in COPD. ${ }^{9}{ }^{10}$ Following hospitalisation for an acute exacerbation, patients are typically less active and more breathless and may remain so for several weeks. ${ }^{11}$ Quadriceps muscle strength commonly falls during an exacerbation $^{12}$ and may contribute to inactivity. ${ }^{13}$ Multidisciplinary pulmonary rehabilitation can improve dyspnoea and quality of life, and can generate clinically meaningful improvements in exercise capacity. ${ }^{414}$ A randomised trial of pulmonary rehabilitation in stable disease demonstrated a reduction in hospital days over a 1 -year period. ${ }^{4}$ The physiological deficits exhibited by patients after a hospital admission are, at least in part, amenable to pulmonary rehabilitation, and their correction may help prevent re-exacerbation.

We have shown in an earlier study that pulmonary rehabilitation administered within a week of hospital discharge can generate improvements in exercise capacity. Emergency department attendances were reduced over a 3-month period and a trend towards reduced hospital admissions was observed. ${ }^{15}$ A meta-analysis of this study and two other reports concluded that post-exacerbation rehabilitation can reduce readmissions. ${ }^{16}$ One study was of a home-based intervention that did not reduce readmissions, and the other reported an inpatient intervention followed by 6 month of outpatient exercise. Such approaches contrast with the typical outpatient pulmonary rehabilitation approach familiar to providers in the UK. We wished to test the hypothesis that pulmonary rehabilitation following a COPD exacerbation can reduce subsequent hospital admissions over a 3-month period. A secondary objective was to investigate whether quadriceps strength increased during post-exacerbation pulmonary rehabilitation (PEPR) and, if so, whether this related to improved exercise capacity.

\section{METHODS \\ Study design}

Following hospitalisation for an acute COPD exacerbation, patients were randomised to receive either usual care (UC) or PEPR initiated within a week of hospital discharge. ${ }^{15}$ Due to the nature of the intervention, it was not possible to blind subjects to their allocation. The primary outcome variable was any exacerbation requiring an individual to be admitted to hospital in the 3 months following the reference admission. Secondary physiological outcome measures required patients to reattend for 
assessment. Only subjects with both baseline and 3-month measurements were included in secondary analyses; no attempt was made to impute missing data. Due to personnel required for these assessments and inevitable patient interaction, it was not possible to fully blind assessors to participant allocation.

\section{Patients}

All participants had a diagnosis of COPD prior to admission. ${ }^{17}$ Patients had a ratio of forced expiratory volume in $1 \mathrm{~s}\left(\mathrm{FEV}_{1}\right)$ to forced vital capacity (FVC) of $<0.7$ and/or the presence of emphysema on high-resolution CT scanning, alongside a selfreported smoking history, clinical signs and symptoms consistent with COPD and exertional dyspnoea (Medical Research Council (MRC) grade 2 or above). Subjects were admitted to hospital for a period in excess of $24 \mathrm{~h}$ and commenced on oral corticosteroid therapy (30-40 mg prednisolone) and/or antibiotic therapy. The use of temporary non-invasive ventilation was not excluded. Participants were willing to enrol on to a pulmonary rehabilitation programme within a week of discharge. Comorbidities precluding exercise testing or training were exclusion criteria, as was attendance at a pulmonary rehabilitation class in the preceding year. ${ }^{15}$

\section{Healthcare utilisation data}

Hospital admission episodes (length of stay $>24 \mathrm{~h}$ ) and other emergency department attendances relating to exacerbations were prospectively captured using both patient diaries and hospital database analysis. Medical note review was used to corroborate length of stay or the nature of any episode where relevant. Exacerbations were defined as any increase in breathlessness, cough or sputum production that led to prescription of oral steroid or antibiotic therapy. Exacerbations managed in the community were not recorded given interclinician discrepancies in diagnostic threshold and the lower health service burden of such events.

\section{Physiological measurements}

Measurements were made within $72 \mathrm{~h}$ of hospital discharge and after 3 months. Non-attendance within 3 weeks of the designated follow-up time was deemed failure to attend. Spirometry $\left(\mathrm{FEV}_{1}, \mathrm{FVC}\right.$ and peak expiratory flow rate (PEFR)), transfer factor (diffusing capacity) for carbon monoxide (TLCO) and lung volume estimation by body plethysmography (total lung capacity (TLC) and residual volume (RV)) were performed according to recommended guidelines ${ }^{18-20}$ following administration of inhaled salbutamol via spacer device. Patients took their inhaled long-acting bronchodilator therapy on the day of testing. Arterialised capillary ear lobe blood samples were obtained for measurement of oxygen and carbon dioxide tensions $\left(\mathrm{PaO}_{2}\right.$ and $\left.\mathrm{PaCO}_{2}\right)$. Patients rated their overall health on the EQ5D ${ }^{21}$ visual analogue scale $(0-100 \%)$ and completed the self-reported Chronic Respiratory Disease ${ }^{22}$ and St George's Respiratory Questionnaires (CRDQ and SGRQ). ${ }^{23}$

Exercise capacity was assessed by externally paced incremental ${ }^{24}$ and endurance shuttle walking tests (ISW and ESW) ${ }^{25}$ A practice walk was performed and tests were separated by a period of at least $30 \mathrm{~min}$. Self-reported dyspnoea and leg fatigue were measured on the modified Borg scale. ${ }^{26}$ Right quadriceps strength was assessed by maximum isometric voluntary contraction force (OMVC). Supine OMVC was measured using the apparatus of Edwards et al. ${ }^{27}$ OMVC was taken as the highest force that could be sustained over $1 \mathrm{~s}$. Whole body fat-free mass (FFM) was estimated by electrical bioimpedance (Bodystat-1500).

\section{Quadriceps muscle substudy}

Participants were also asked to consent to a more detailed quadriceps muscle assessment. Supramaximal stimulation of the femoral nerve was performed to generate quadriceps twitch responses $(\mathrm{TwQ}) .{ }^{28}$ Unpotentiated twitches were obtained using a $70 \mathrm{~mm}$ figure-of-eight coil (Magstim Co, Whitland, UK) following 20 min of rest. A measure of volitional muscle activation during the OMVC, twitch interpolation (TwInt), ${ }^{29}$ was obtained by superimposition of a magnetically-induced twitch.

\section{Participating centres and pulmonary rehabilitation}

Two physiotherapists (LM, JC) working between three hospitals (King's College, St Thomas' and Basildon) coordinated and supervised the hospital-led PEPR programme. Local research ethics committee approval was obtained from these institutions. Participants were incorporated into standard pulmonary rehabilitation classes consisting of twice-weekly exercise and education sessions (each lasting $2 \mathrm{~h}$ ) for a period of 8 weeks. Exercise was a mixture of limb strengthening and aerobic activities, tailored to individual baseline function. To anticipate missed classes, the number of sessions completed before the 3-month assessment was recorded. Patients in both the UC and PEPR groups were provided with general information about COPD prior to randomisation and offered outpatient appointments with their general practitioner or respiratory team.

\section{Sample size calculation, patient allocation and statistical methods}

Based on our previous study, ${ }^{15}$ we estimated that 30 subjects were required in each arm to give $80 \%$ power at the $5 \%$ significance level for detecting a $50 \%$ reduction in exacerbations requiring hospital admission. Participants were allocated by concealed randomisation by a statistician. The minimisation method matched groups for age ( $<70$ or $\geq 70$ years), sex (male or female), predicted $\mathrm{FEV}_{1}(<30 \%$ or $\geq 30 \%)$, duration of admission $(<7$ or $\geq 7$ days) and baseline ISW distance $(<100 \mathrm{~m}$ or $\geq 100 \mathrm{~m}$ ). Participants were analysed on an intention-to-treat basis regardless of compliance. Exacerbation data were analysed by binary logistic regression. Between-group analysis of secondary outcomes employed analysis of covariance. Where baseline variables differed between groups, both allocation and baseline values were entered as co-variables. Pearson coefficients described the relationship between the change in quadriceps strength (QMVC) and change in ISW distance or FFM. Statistical significance was accepted for $p$ values $<0.05$.

\section{RESULTS}

Sixty-one patients consented to enter the study between June 2005 and April 2008; one patient died before randomisation. Healthcare utilisation data were collected for 60 patients. Figure 1 illustrates patients analysed for primary and secondary outcomes and table 1 summarises their baseline characteristics. The number of exacerbations requiring admission in the preceding year was $0-5$ for patients in the UC arm and $0-6$ for those allocated to PEPR. Seventy-two percent of all participants were prescribed a combination of inhaled corticosteroid and long-acting bronchodilator therapy; 25\% took a long-acting bronchodilator without inhaled corticosteroid. The most commonly recorded comorbid conditions were hypertension $(\mathrm{N}=22)$, stable treated ischaemic heart disease $(\mathrm{N}=13)$ and type 2 diabetes mellitus $(\mathrm{N}=10)$. Six patients had received temporary non-invasive ventilation during their reference admission. The number of rehabilitation classes attended in the PEPR arm 
Figure 1 Trial profile illustrating patients with chronic obstructive pulmonary disease (COPD) analysed for primary and secondary study outcomes. PEPR, post-exacerbation pulmonary rehabilitation.

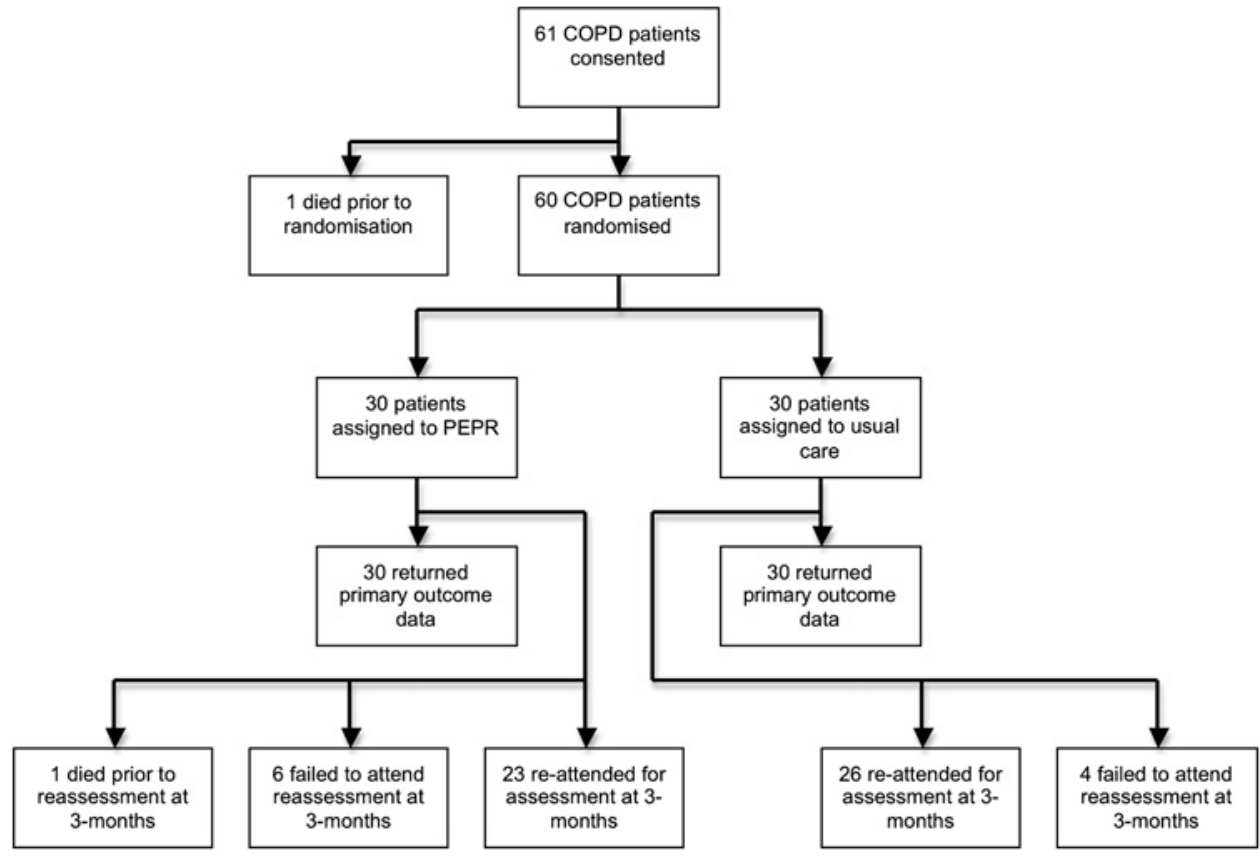

ranged between 1 and 16 (median 15). The programme completion rate in the PEPR arm using a standard cut-off of $50 \%$ classes attended was $77 \%$.

\section{Healthcare utilisation}

Twelve patients experienced at least one hospital admission for COPD exacerbation within 3 months of their index admission. Among those not readmitted, a further 13 patients were treated for at least one exacerbation in the emergency department. The proportion of patients experiencing at least one hospital admission for a COPD exacerbation over 3 months was lower in the PEPR group than in the UC group ( $7 \%$ vs $33 \%, p=0.02$; table 2). The number of subjects attending the emergency department (without being admitted) was similar; however, the

Table 1 Baseline characteristics of patients with COPD

\begin{tabular}{|c|c|c|}
\hline & UC $(N=30)$ & PEPR $(\mathrm{N}=\mathbf{3 0})$ \\
\hline Age (years) & $65(10)$ & $67(10)$ \\
\hline $\operatorname{Sex}(M: F)$ & $14: 16$ & 13:17 \\
\hline Recruitment site $(1: 2: 3)$ & $16: 13: 1$ & $18: 9: 3$ \\
\hline Median (IQR) admission length (days) & $5(4-8)$ & $6(4-8)$ \\
\hline $\begin{array}{l}\text { Median (IQR) no of admissions in previous } \\
\text { year }\end{array}$ & $1(0-3)$ & $1(0-2)$ \\
\hline Median (IQR) smoking pack-years & $40(23-57)$ & $44(30-61)$ \\
\hline Smoking status (active:prior) & 10:20 & $11: 19$ \\
\hline $\mathrm{FEV}_{1}(\mathrm{I})$ & $1.3(0.6)$ & $1.2(0.4)$ \\
\hline $\mathrm{FEV}_{1}$ (\%predicted) & $52(22)$ & $52(20)$ \\
\hline $\mathrm{SaO}_{2}(\%)$ & $95(3)$ & $94(2)$ \\
\hline MRC dyspnoea score (range 1-5) & $3.2(0.7)$ & $3.6(0.8)$ \\
\hline BMI $\left(\mathrm{kg} / \mathrm{m}^{2}\right)$ & $28.7(7.8)$ & $29.1(9.1)$ \\
\hline FFMI $\left(\mathrm{kg} / \mathrm{m}^{2}\right)$ & $17.6(3.0)$ & $18.1(3.2)$ \\
\hline ISW (m) & $159(93)$ & $147(89)$ \\
\hline OMVC $(\mathrm{kg})$ & $24.6(13.2)$ & $22.0(6.8)$ \\
\hline SGRO total score (aU) & $59.0(16.1)$ & $61.9(17.2)$ \\
\hline
\end{tabular}

Data shown are mean (SD) unless otherwise indicated

Three UK sites participated: (1) King's College Hospital, (2) St Thomas' Hospital and (3) Basildon Hospital.

$\mathrm{BMI}$, body mass index; $\mathrm{FEV}_{1}$, forced expiratory volume in $1 \mathrm{~s}$; FFMI, fat-free mass index: ISW, incremental walking capacity; PEPR, post-exacerbation pulmonary rehabilitation; OMVC, quadriceps maximum voluntary contraction; $\mathrm{SaO}_{2}$, arterial oxygen saturation; $\mathrm{SGRO}$, St George's Respiratory Questionnaire; UC, usual care.
UC patients attended earlier after discharge (median +16 days compared with +48 days in the PEPR group, $p<0.01)$. The number of subjects experiencing at least one emergency hospital attendance of any type was lower in the PEPR group than in the UC group ( $27 \%$ vs $57 \%$, $\mathrm{p}=0.02)$. The median time to any event was shorter in the UC arm than in the PEPR arm ( +29 days vs +52 days, $p=0.03$ ). Nine subjects in the UC group reported more than one unplanned emergency hospital attendance: the mean number of exacerbation events per subject was lower in the PEPR arm than in the UC arm $(0.27$ vs $1.1, \mathrm{p}<0.01)$.

\section{Quadriceps strength, exercise capacity and quality of life}

Follow-up physiological data were obtained in 26 patients receiving UC (46\% male, mean (SD) age 65 (10) years, $53(21) \%$ predicted $\mathrm{FEV}_{1}$ ) and 23 patients (44\% male, mean (SD) age 68 (10) years, $52(20) \%$ predicted $\mathrm{FEV}_{1}$ ) undergoing PEPR. No pulmonary function test changed significantly between groups (see table $\mathrm{E} 1$ in the online supplement). Technically satisfactory gas transfer and body plethysmography measurements immediately following exacerbation were obtainable in only $63 \%$ and $51 \%$ of subjects, respectively. Table 3 shows the change in quadriceps strength, walking capacity and quality of life; no improvement was observed in the UC group. Compared with UC, patients in the PEPR group demonstrated an increase in OMVC $(5.1 \mathrm{~kg}, 95 \%$ CI 2.5 to $7.6, \mathrm{p}<0.01)$, ISW (51 kg, 95\% CI 22 to $79, p<0.01)$ and ESW (189 kg, 95\% CI 28 to $350, p=0.02)$. PEPR was associated with an improved SGRQ total and activities score as well as increased CRDQ dyspnoea and emotion scores.

Although FFM and OMVC correlated at baseline $(\mathrm{r}=0.65$, $\mathrm{p}<0.01)$ and 3 months $(\mathrm{r}=0.62, \mathrm{p}<0.01)$, OMVC change and FFM change were unrelated. The change in OMVC was significantly correlated with the change in ISW $(r=0.40, p<0.01$, figure 2). In all patients a fall in quadriceps strength was more likely if a re-exacerbation event occurred (OR 3.87, 95\% CI 1.01 to $12.2, \mathrm{p}=0.049$ ).

\section{Quadriceps substudy}

Table 4 shows the subjects who participated in the quadriceps substudy and in whom supramaximal twitch responses were 
Table 2 Healthcare utilisation in the UC and PEPR arms over 3 months

\begin{tabular}{llll}
\hline & \multicolumn{2}{l}{ Number (\% subjects within group) } & OR (95\% CI) PEPR vs UC* \\
\cline { 2 - 4 } & UC (N=30) & PEPR (N=30) & $0.15(0.03$ to 0.72$)$ \\
\hline Hospital admission for exacerbation & $10(33 \%)$ & $2(7 \%)$ & $0.66(0.18$ to 2.36$)$ \\
ED attendance for exacerbation & $7(23 \%)$ & $6(20 \%)$ & $0.28(0.10$ to 0.82$)$ \\
Hospital or ED attendance for exacerbation & $17(57 \%)$ & $8(27 \%)$ & 0.52 \\
\hline
\end{tabular}

*Binary logistic regression: $\operatorname{expB}(95 \% \mathrm{Cl}$ for ExpB).

Numbers and percentages refer to the proportion of patients experiencing at least one event of each type. Emergency department attendances were episodes not requiring admission. ED, emergency department; PEPR, post-exacerbation pulmonary rehabilitation; UC, usual care.

obtained. The increase in quadriceps strength associated with PEPR remained significant $(\mathrm{p}<0.01)$ after adjustment for the observed difference in baseline OMVC, both in the main study and among the patients in the substudy. Both $\mathrm{TwO}(+2.2 \mathrm{~kg}$, $95 \%$ CI 0.9 to $3.5, \mathrm{p}<0.01)$ and muscle activation measured by TwInt $(0.0795 \%$ CI 0.01 to $0.14, p=0.04)$ increased in the PEPR group compared with the UC group.

\section{DISCUSSION}

This study shows that pulmonary rehabilitation administered shortly after an acute exacerbation of COPD is associated with a reduced frequency of re-exacerbation that requires hospital admission or attendance in the subsequent 3 months. Our previous work showed that rehabilitation given in this manner was associated with increased exercise capacity and quality of life. ${ }^{15}$ The current study extends these findings and observes that quadriceps muscle strength is increased by PEPR and may, at least in part, underlie the observed increase in exercise capacity.

The hospital readmission rate, although consistent with previous audit in the UK, was lower than that observed in our previous study. ${ }^{15}$ Lower $\mathrm{FEV}_{1}$ is a risk factor for readmission, ${ }^{9}$ and the present cohort had less severe COPD (predicted $\mathrm{FEV}_{1}$ approximately $50 \%$ compared with $40 \%$ in the previous study). While there was no intent to recruit less severe patients, COPD patients with more severe disease may have been less willing to participate, especially pulmonary rehabilitation-naïve individ- uals. The present study found that emergency department attendances not requiring admission were unaltered, in contrast to our earlier report. ${ }^{15}$ The balance between emergency department attendance and hospital admission may be altered by supported discharge schemes, ${ }^{30}$ which were present at the host institutions throughout the current and previous studies. Such schemes were not operational at all times, and it is unclear if the results of this study are applicable only to patients unsuitable for supported discharge. Neither can an estimate of eligible patients for PEPR be derived from screening. The study accessed existing rehabilitation capacity and, as such, screening of acute COPD admissions was not a continuous activity.

This study cannot definitively say whether psychological or physiological changes brought about by the PEPR programme were responsible for the change in healthcare utilisation. It is clear that most of the patients in the PEPR group had frequent contact with healthcare professionals over the reporting period. A meta-analysis of smaller heterogenous randomised controlled studies reported a pooled OR for readmission of 0.13 , similar to that observed here. ${ }^{16}$ The PEPR interventions included in this meta-analysis were a mixture of inpatient, outpatient and home-based interventions; interestingly, the latter did not demonstrate a reduction in readmissions.

The cost-effectiveness of PEPR was challenging to assess. Based on the current UK National Health Service payment-by-results structure (http://www.dh.gov.uk/en/Publicationsandstatistics/ Publications/PublicationsPolicyAndGuidance/DH_081096), the

Table 3 Incremental and endurance walking capacity, fat-free mass, quadriceps strength and quality of life at baseline and 3 months

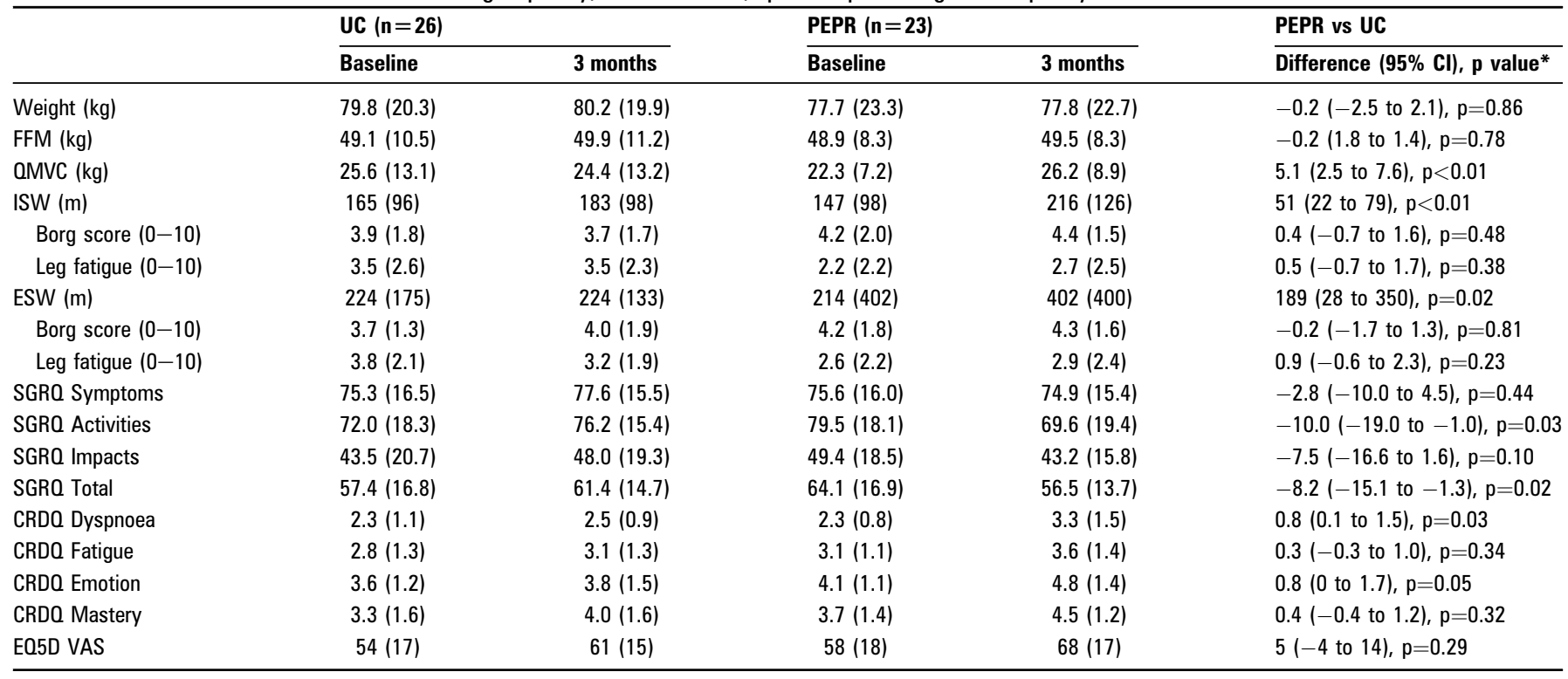

*ANCOVA.

Within group differences and differences between UC and PEPR groups shown.

CRDQ, Chronic Respiratory Disease Questionnaire; ESW, endurance walking capacity; FFMI, fat-free mass index; ISW, incremental walking capacity; PEPR, post-exacerbation pulmonary rehabilitation; QMVC, quadriceps maximum voluntary contraction; SGRQ, St George Respiratory Questionnaire; UC, usual care; VAS, visual analogue scale. 


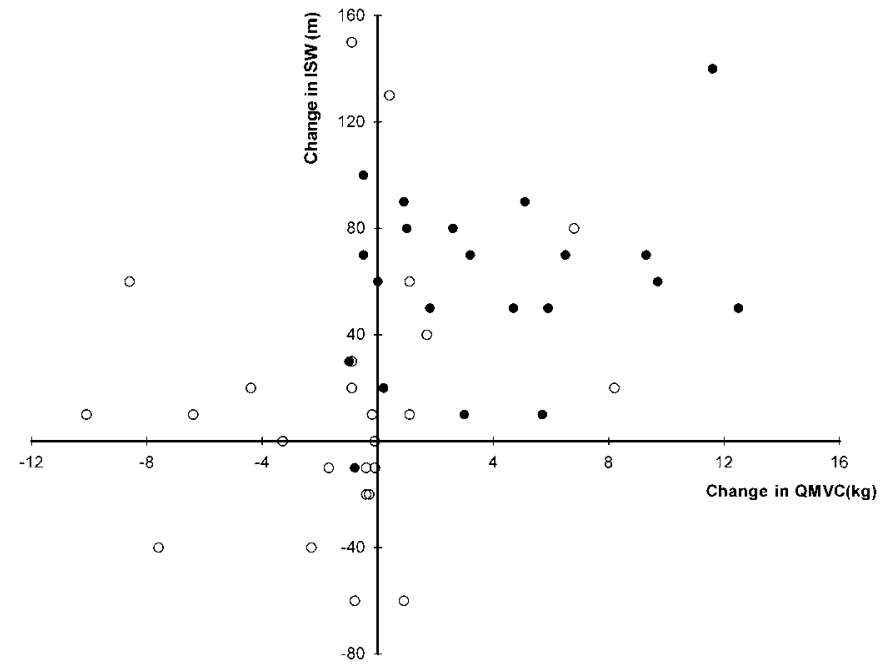

Figure 2 Scatterplot showing the relationship between the change in quadriceps maximum voluntary contraction strength (OMVC) and the change in incremental shuttle walking test performance (ISW). Filled circles indicate subjects in the post-exacerbation pulmonary rehabilitation group; open circles represent individuals in the usual care group.

cost associated with the additional observed COPD exacerbation episodes in the UC group over 3 months equated to $£ 35268$. No national tariff is attached to pulmonary rehabilitation programmes, and their structure and provision are subject to local variation. Existing programmes were accessed during this study; the per-patient cost of providing rehabilitation depends on programme capacity, which varied across participating centres.

Maximal walking capacity measured by ISW was increased in the PEPR group. The difference between groups in ISW performance was $51 \mathrm{~m}$, which exceeds the minimum clinically important difference for this test. ${ }^{31}$ Assessor blinding was not possible for all patients; however, the ISW is externally paced and reproducible and practice walks were also performed. A randomised trial of pulmonary rehabilitation in the UK reported a similar mean increase of $71 \mathrm{~m}$ in stable disease. Selfreported dyspnoea on the Borg scale suggested a degree of desensitisation to exertional dyspnoea associated with this improvement. Alternatively, improvement in peripheral muscle function and hence lactate production, particularly from the quadriceps, ${ }^{32} 33$ could provide a physiological explanation for reduced ventilatory drive. Quadriceps endurance properties were not measured. No significant change in static pulmonary function was observed, but many patients struggled to perform adequate gas transfer or body plethysmography measurements following exacerbation. Dynamic inspiratory capacity measurements were not performed. ${ }^{34}$

ISW performance depends, at least in part, on quadriceps strength. ${ }^{35}$ The present study showed a relationship between the change in quadriceps strength and change in walking performance. An increase in muscle strength following training is commonly achieved through increased volitional drive. ${ }^{36}$ The change in OMVC was associated with an increase in the twitch response to femoral nerve stimulation, suggesting that contractility had increased. However, whole-body muscle mass estimated by bioimpedance was similar. Competing but not mutually exclusive explanations could involve a change in muscle fibre orientation ${ }^{37}$ or, more likely, a localised increase in quadriceps muscle volume that bioimpedance was too insensitive to detect. Direct measurement of leg muscle volume would have addressed this.

A key limitation of the study is that physiological variables were unknown prior to admission. For example, the $17 \%$ increase in OMVC observed in the PEPR group may represent recovered muscle strength lost during admission or improvement above baseline. Healthy subjects lose $16 \%$ of isokinetic muscle strength during 10 days of bed rest, ${ }^{38}$ while patients with COPD have been reported to lose $5 \%$ of their predicted quadriceps force during an exacerbation. ${ }^{12}$ Inactivity is prominent during exacerbations and contributes to the development of weakness. In the present study, subsequent exacerbations requiring emergency department attendance or admission were associated with a reduction in quadriceps strength and would support a model whereby recurrent exacerbations lead to a downward functional spiral and loss of physiological reserve. This assertion is supported by accelerometry studies reporting reduced weight-bearing activity 1 month after an exacerbation, and an association of such activity with quadriceps strength. ${ }^{11}$ Accelerometry was not performed in this study to assess whether change in daily activity related to change in exercise capacity or quadriceps strength.

\section{CONCLUSION}

Outpatient pulmonary rehabilitation immediately following an acute COPD exacerbation can reduce the risk of re-exacerbation requiring hospital attendance in the following 3 months. Exercise capacity and quadriceps strength, factors known to predict reduced healthcare utilisation in stable disease, can be improved by this intervention. The longevity of these effects remains to be determined, as does the minimum duration of PEPR required. While outpatient pulmonary rehabilitation for stable patients in the UK and elsewhere has been shown to be clinically and costeffective, ${ }^{14}{ }^{39}$ the benefits for many decline with time and may be eroded by disease exacerbation. Longer studies could evaluate whether post-hospitalisation 'rescue rehabilitation' can better maintain or prolong the benefits of pulmonary rehabilitation administered in stable disease.

Funding JMS was funded by a British Lung Foundation Project Grant (P04/8). CJJ was funded by the Medical Research Council UK. JSS was funded by the European Respiratory Society. WDCM was funded by the Medical Research Council UK and the National Institute for Health. Study design, conduct, analysis and reporting were independent of the project sponsor (King's College London) and funder (British Lung Foundation). MIP's salary is part funded by the Respiratory Biomedical Research Unit of the Royal Brompton Hospital and Imperial College.

Table 4 Quadriceps maximum voluntary contraction (OMVC), quadriceps twitch response to femoral nerve stimulation and voluntary muscle activation during a OMVC (Twint) at baseline and 3 months

\begin{tabular}{|c|c|c|c|c|c|}
\hline & \multicolumn{2}{|l|}{ UC $(n=12)$} & \multicolumn{2}{|c|}{ PEPR $(n=11)$} & \multirow{2}{*}{$\begin{array}{l}\text { PEPR vs UC } \\
\text { Difference }(95 \% \mathrm{Cl}), \mathrm{p} \text { value* }\end{array}$} \\
\hline & Baseline & 3 months & Baseline & 3 months & \\
\hline OMVC $(\mathrm{kg})$ & $29.0(14.2)$ & $27.8(15.2)$ & $24.5(6.3)$ & $30.4(8.1)$ & 7.3 (3.2 to 11.5$), p<0.01$ \\
\hline Tw0 (kg) & $8.8(4.0)$ & $8.2(3.4)$ & $6.9(2.7)$ & $8.7(3.0)$ & $2.2(0.9$ to 3.5$), \mathrm{p}<0.01$ \\
\hline
\end{tabular}

${ }^{*}$ ANCOVA (covariates: allocation group and baseline value).

PEPR, post-exacerbation pulmonary rehabilitation; QMVC, quadriceps maximum voluntary contraction; Twlnt, twitch interpolation; Tw0, quadriceps twitch; UC, usual care. 


\section{Competing interests None.}

Ethics approval This study was conducted with the approval of the King's College Hospital REC, Basildon and Thurrock University Hospitals REC (SSA), St Thomas' Hospitals REC (SSA).

Contributors JMS conducted the research and was responsible for data collection, analysis and manuscript preparation. LM and JC were responsible for data collection. CJJ and JSS were responsible for data collection and assisted in the preparation of the manuscript. WDCM, JM and MIP were responsible for the trial design and manuscript preparation. NH and BY were principal investigators at participating sites. $\mathrm{JM}$ was the chief investigator and is responsible for the final content of the manuscript.

Provenance and peer review Not commissioned; externally peer reviewed.

\section{REFERENCES}

1. Murray CJ, Lopez AD. Alternative projections of mortality and disability by cause 1990-2020: Global Burden of Disease Study. Lancet 1997;349:1498-504.

2. Calverley PM, Anderson JA, Celli B, et al. Salmeterol and fluticasone propionate and survival in chronic obstructive pulmonary disease. N Engl J Med 2007;356:775-89.

3. Tashkin DP, Celli B, Senn S, et al. A 4-year trial of tiotropium in chronic obstructive pulmonary disease. N Engl J Med 2008;359:1543-54.

4. Griffiths TL, Burr ML, Campbell IA, et al. Results at 1 year of outpatient multidisciplinary pulmonary rehabilitation: a randomised controlled trial. Lancet 2000;355:362-8.

5. Bourbeau J, Julien M, Maltais F, et al. Reduction of hospital utilization in patients with chronic obstructive pulmonary disease: a disease-specific self-management intervention. Arch Intern Med 2003;163:585-91.

6. Seemungal TA, Donaldson GC, Bhowmik A, et al. Time course and recovery of exacerbations in patients with chronic obstructive pulmonary disease. Am J Respir Crit Care Med 2000;161:1608-13.

7. Spencer S, Jones PW. Time course of recovery of health status following an infective exacerbation of chronic bronchitis. Thorax 2003;58:589-93.

8. Price LC, Lowe D, Hosker HS, et al. UK National COPD Audit 2003: impact of hospital resources and organisation of care on patient outcome following admission for acute COPD exacerbation. Thorax 2006;61:837-42.

9. Garcia-Aymerich J, Farrero E, Felez MA, et al. Risk factors of readmission to hospital for a COPD exacerbation: a prospective study. Thorax 2003;58:100-5.

10. Decramer M, Gosselink R, Troosters T, et al. Muscle weakness is related to utilization of health care resources in COPD patients. Eur Respir J 1997;10:417-23.

11. Pitta F, Troosters T, Probst VS, et al. Physical activity and hospitalization for exacerbation of COPD. Chest 2006;129:536-44.

12. Spruit MA, Gosselink $R$, Troosters $T$, et al. Muscle force during an acute exacerbation in hospitalised patients with COPD and its relationship with CXCL8 and IGF-I. Thorax 2003;58:752-6.

13. Gosselink R, Troosters T, Decramer M. Peripheral muscle weakness contributes to exercise limitation in COPD. Am J Respir Crit Care Med 1996:153:976-80.

14. Lacasse Y, Goldstein R, Lasserson TJ, et al. Pulmonary rehabilitation for chronic obstructive pulmonary disease. Cochrane Database Syst Rev 2006:CD003793.

15. Man WD, Polkey Ml, Donaldson N, et al. Community pulmonary rehabilitation after hospitalisation for acute exacerbations of chronic obstructive pulmonary disease: randomised controlled study. BMJ 2004;329:1209.

16. Puhan M, Scharplatz M, Troosters T, et al. Pulmonary rehabilitation following exacerbations of chronic obstructive pulmonary disease. Cochrane Database Syst Rev 2009:CD005305

17. Pauwels RA, Buist AS, Calverley PM, et al. Global strategy for the diagnosis, management, and prevention of chronic obstructive pulmonary disease. NHLBI/WHO global initiative for chronic obstructive lung disease (GOLD) workshop summary. Am J Respir Crit Care Med 2001;163:1256-76.

18. Miller MR, Hankinson J, Brusasco V, et al. Standardisation of spirometry. Eur Respir J 2005:26:319-38.

19. Macintyre N, Crapo RO, Viegi G, et al. Standardisation of the single-breath determination of carbon monoxide uptake in the lung. Eur Respir $\mathrm{J} 2005$; 26:720-35.

20. Wanger J, Clausen JL, Coates A, et al. Standardisation of the measurement of lung volumes. Eur Respir J 2005:26:511-22.

21. Anon. EuroOol-a new facility for the measurement of health-related quality of life The EuroOol group. Health Policy 1990;16:199-208.

22. Guyatt GH, Berman LB, Townsend $\mathrm{M}$, et al. A measure of quality of life for clinical trials in chronic lung disease. Thorax 1987;42:773-8.

23. Jones PW, Quirk FH, Baveystock CM. The St George's Respiratory Questionnaire. Respir Med 1991;85(Suppl B):25-31.

24. Singh SJ, Morgan MD, Scott $S$, et al. Development of a shuttle walking test of disability in patients with chronic airways obstruction. Thorax 1992; 47:1019-24.

25. Revill SM, Morgan MD, Singh SJ, et al. The endurance shuttle walk: a new field test for the assessment of endurance capacity in chronic obstructive pulmonary disease. Thorax 1999:54:213-22.

26. Borg GA. Psychophysical bases of perceived exertion. Med Sci Sports Exerc 1982;14:377-81.

27. Edwards RH, Young A, Hosking GP, et al. Human skeletal muscle function: description of tests and normal values. Clin Sci Mol Med 1977;52:283-90.

28. Polkey MI, Kyroussis D, Hamnegard $\mathrm{CH}$, et al. Quadriceps strength and fatigue assessed by magnetic stimulation of the femoral nerve in man. Muscle Nerve 1996;19:549-55

29. Herbert RD, Gandevia SC. Twitch interpolation in human muscles: mechanisms and implications for measurement of voluntary activation. J Neurophysiol 1999:82:2271-83.

30. Cotton MM, Bucknall CE, Dagg KD, et al. Early discharge for patients with exacerbations of chronic obstructive pulmonary disease: a randomized controlled trial. Thorax 2000;55:902-6.

31. Singh SJ, Jones PW, Evans R, et al. Minimum clinically important improvement for the incremental shuttle walking test. Thorax 2008;63:775-7.

32. Maltais $\mathbf{F}$, LeBlanc $P$, Whittom F, et al. Oxidative enzyme activities of the vastus lateralis muscle and the functional status in patients with COPD. Thorax 2000;55:848-53.

33. Saey D, Michaud A, Couillard A, et al. Contractile fatigue, muscle morphometry, and blood lactate in chronic obstructive pulmonary disease. Am J Respir Crit Care Med 2005:171:1109-15.

34. Stevenson NJ, Walker PP, Costello RW, et al. Lung mechanics and dyspnea during exacerbations of chronic obstructive pulmonary disease. Am J Respir Crit Care Med 2005:172:1510-16.

35. Steiner MC, Singh SJ, Morgan MD. The contribution of peripheral muscle function to shuttle walking performance in patients with chronic obstructive pulmonary disease. J Cardiopulm Rehabil 2005;25:43-9.

36. Gandevia SC. Spinal and supraspinal factors in human muscle fatigue. Physiol Rev 2001:81:1725-89.

37. Aagaard P, Andersen JL, Dyhre-Poulsen P, et al. A mechanism for increased contractile strength of human pennate muscle in response to strength training: changes in muscle architecture. J Physiol 2001:534:613-23.

38. Kortebein P, Ferrando A, Lombeida J, et al. Effect of 10 days of bed rest on skeletal muscle in healthy older adults. JAMA 2007;297:1772-4.

39. Griffiths TL, Phillips CJ, Davies S, et al. Cost effectiveness of an outpatient multidisciplinary pulmonary rehabilitation programme. Thorax 2001;56:779-84. 